\title{
Predictive factors of diagnostic and therapeutic divergence in a nationwide cohort of patients seeking second medical opinion
}

Stéphane Sanchez ${ }^{1 *}$, Isabelle Adamowicz ${ }^{2}$, Jan Chrusciel ${ }^{1}$, Philippe Denormandie ${ }^{3}$, Pierre Denys ${ }^{4}$ and Laurent Degos ${ }^{5}$

\begin{abstract}
Objectives: The aim of this study was to describe the profile of patients who sought a second medical opinion (SMO) on their therapeutic or diagnostic strategy using nationwide data from a French physician network dedicated to SMOs.

Methods: An observational cohort study was conducted and the study population consisted of patients residing in France or in the French overseas territories who submitted a request for an $\mathrm{SMO}$ through a dedicated platform between January 2016 and October 2020. Patient characteristics were compared between convergent and divergent SMOs. The divergent rate for all patients excluding those with mental diseases were described. Logistic regression was used to estimate the probability of a divergent SMO according to patient characteristics.

Results and discussion: In total, 1,552 adult patients over several French regions were included. The divergence rate was $32.3 \%$ ( $n=502$ patients). Gynecological [Odds Ratio (OR) and $95 \%$ Cl: 5.176 (3.154 to 8.494)], urological [OR 4.246 (2.053 to 8.782)] and respiratory diseases [OR 3.639 (1.357 to 9.758)] had the highest probability of a divergent SMO. Complex cases were also associated with a significantly higher risk of a divergent opinion [OR 2.78 (2.16 to 3.59)]. Age, sex, region and profession were not found to be predictive of a divergent second opinion.
\end{abstract}

Conclusions: Policymakers should encourage new research on patient outcomes such as mortality and hospitalization rates after a SMO. When proven effective, SMO networks will have the potential to benefit from specific public funding or even play a key role in national healthcare quality improvement programs.

\section{Introduction}

An expert second medical opinion (SMO) enables a patient to confirm or re-evaluate a diagnosis and/or a treatment recommended by a general practitioner (GP) or specialist. The practice of seeking an SMO has been described in literature for a range of disease types [1-

\footnotetext{
* Correspondence: Stephane.sanchez@hcs-sante.fr

'Public Health and Performance Department, Champagne Sud Hospitals, 101 avenue Anatole France, 10000 Troyes, France

Full list of author information is available at the end of the article
}

12], with different approaches according to the source of the referral given (patient or doctor), level of specialization of the physician performing the SMO (general practitioner or another specialist) and the modality of the second analysis (consultation or history and chart review) $[3,9]$. In the United States, SMOs were first known as a way to control rising healthcare costs, for example by preventing unnecessary elective surgery and for this purpose SMOs were mandatory for

C C The Author(s). 2021 Open Access This article is licensed under a Creative Commons Attribution 4.0 International License, which permits use, sharing, adaptation, distribution and reproduction in any medium or format, as long as you give appropriate credit to the original author(s) and the source, provide a link to the Creative Commons licence, and indicate if changes were made. The images or other third party material in this article are included in the article's Creative Commons licence, unless indicated otherwise in a credit line to the material. If material is not included in the article's Creative Commons licence and your intended use is not permitted by statutory regulation or exceeds the permitted use, you will need to obtain permission directly from the copyright holder. To view a copy of this licence, visit http://creativecommons.org/licenses/by/4.0/ The Creative Commons Public Domain Dedication waiver (http://creativecommons.org/publicdomain/zero/1.0/) applies to the data made available in this article, unless otherwise stated in a credit line to the data. 
Medicaid recipients in the $1980 \mathrm{~s}$ but later appeared as a way to improve healthcare quality [13].

SMO can result in a change of diagnosis, treatment or prognosis in $10-62 \%$ of cases [6]. This wide variation may be due to healthcare provider divergence, variations in the quality of the methodology used in the studies, or having small sample sizes.

A German study, where the cost of SMOs were stated to be paid either by insurance companies or the patient, found that $64.8 \%$ of the initial therapeutic strategies were not confirmed in the second opinion consultations. In this study, SMOs were sought primarily for orthopedic conditions (knee, spine, hip and shoulder) with an agreement rate as low as $26.2 \%$ for the most common family of conditions in the program (diseases of the knee) [14].

In Israel, SMOs are funded either through the universal National Health Insurance, voluntary insurances programs or out-of-pocket payments. A cross-sectional study conducted on a representative random sample of the general adult population reported that $56 \%$ of 305 SMO seekers considered that there was a difference in diagnosis or treatment between the first opinion and the second consultations. Ophthalmologic and gynecological motives were also frequent in this study (9 and $8.1 \%$ respectively, after orthopedics which accounted for $32.3 \%$ of the sample) [15].

In another population-based study conducted in Israel, the type of insurance did not influence divergence rates for most specialties, with the exception of a notably higher divergence rate for neurological disease in patients who asked for a second opinion with their supplementary insurance ( $9 \%$ vs. $3 \%$ ) [16].

Cancer patients are well represented among second opinion seekers, and there is a high potential for changes to the initial therapeutic strategy. Breast cancer, has been associated with a wide use of SMOs, especially at the early stage $[4,8,10]$. For example, in a breast cancer consultation study, $43 \%$ of patients had a change of diagnosis and $23 \%$ had an additional tumor found by a SMO [4]. Although self-referral to a second physician could be associated with higher sensitivity in cancer detection [10], targeted SMO referral strategies in breast cancer cases may have a more favorable profile in cost-benefit analyses [8]. The potential for therapeutic change is also clear for less frequent cancers. A study conducted in a reference cancer treatment center in the US recruited two surgeons to review second opinion radiological assessments of pancreatic ductal adenocarcinoma. Upon seeing the second opinion evaluation, they proposed a change of the patients' management recommendation in 38,4 and $20.0 \%$ of cases respectively [17].

Higher education status, socio-economic status and female gender [5] have, to date, been associated to the characteristics of patients that seek an SMO during diagnosis $[5,9]$.
Understanding which class of diseases may require an SMO to improve healthcare quality could help with the efficient care planning as patients who have divergent SMO also show higher healthcare expenses [3]. The class of diseases where the percentage of divergence is higher could therefore be a target for quality improvement interventions. The evidence on situations where the benefit of an SMO outweighs the cost of an additional consultation is, however, still limited [18-20]. The aim of this study was to describe the profile of patients who sought a SMO on their therapeutic or diagnostic strategy using nationwide data from a French physician network dedicated to SMOs.

\section{Methods}

\section{Study population}

A prospective observational cohort study was conducted using nationwide data from a French SMO platform (https://www.deuxiemeavis.fr/). Patients were included if they resided in France or an overseas French territory and submitted a request for an SMO through the platform between 1 and 2016 and 1 October 2020. All participants consented to the use of their data for research purposes. Mental health disorders were not subject to a SMO in accordance with the existing literature [12].

\section{SMO platform process}

Patients accessed the SMO platform online via a secure connection after creating a free personal account. Patients were then asked their category of disease and their choice from a list of SMO experts. They completed a detailed medical questionnaire related to their concerns and were encouraged to ask the medical inquiries they wanted to obtain an SMO for. Patients could add relevant medical examinations to their request. The Second Look network has 220 experts in various French public and private hospitals and healthcare centers. These experts were selected according to their academic position, clinical experience, international activities and approval by a scientific jury. The SMO platform also partnered with a variety of private insurers to obtain consultations at competitive prices for its patients.

A designated expert was then notified and could either accept or decline the request. If the request was accepted by the expert, a medical analysis of the request was performed. A secure messaging system was available in case additional information was required by the expert. The expert completed a written report which was then shared with the patient. The report stated if the SMO was convergent or divergent. The expert was also asked to rank the level of complexity of the SMO. The patient had the possibility to message the expert back in case of additional questions. 
The SMO report was also sent to the patients' general practitioner (GP) with the patient's consent. The patients were also asked to rate their satisfaction with the SMO platform at case completion.

\section{Data collection}

The following variables were recorded for all case submitted: disease, class of diseases, expert name, level of complexity (simple or complex), divergent or convergence of the SMO, and time duration of the review. For each patient, the age, sex, region of residence, employment category, and whether the GP was aware that the patient was seeking an SMO or not, were collected.

The dependent variable used for statistical modelling was convergence or divergence of both diagnosis and treatment between the first and second opinion. For each case, if the diagnosis and treatment were fully consistent between the first and second opinion, the dependent variable was coded as convergent. In all other cases (diagnostic and/or therapeutic divergence) the dependent variable was coded as divergent.

The dependent variable was designed as a binary variable and directly coded as such during data collection. No quantitative divergence scale was used, therefore there was no need to determine a specific threshold to use for the study.

\section{Statistical analysis}

Quantitative variables were presented as median and 1st and 3rd quartiles (Q1, Q3) if non-normally distributed, and qualitative variables were presented as number (\%). We compared patient characteristics between convergent and divergent SMO. Groups were compared using the chi square or Fisher's exact test as appropriate, and the Mann-Whitney U test was used to compare the time required to prepare the SMO. A planned exploratory analysis was performed to compare simple and complex cases.

Logistic regression was used to estimate the probability of a divergent SMO according to patient characteristics. Missing data were handled by multiple imputation with $\mathrm{m}=100$ imputations. All analyses were performed using $\mathrm{R}$ version 4.0.2 (www.R-project.org). Multiple imputation was performed with the mice package (Stefan Van Buuren).

\section{Ethical considerations}

The database used for this study was fully anonymous. The SMO platform received special authorization from the French national commission for data privacy (Commission Nationale Informatique et Libertés, CNIL) when it was launched (at the beginning of 2016), in compliance with a legislative requirement that has since been lifted. Patients provided informed consent that their anonymous data may be used for research and quality improvement purposes. No additional approvals were required according to the French legislation. According to the ethical rules of the SMO platform scientific council, an SMO expert was not allowed to be directly in charge of the patient.

\section{Results}

A total of 1,552 patients were included in the study. The divergence rate was $32.3 \%$ (502/1552 patients). The main characteristics of the study population are shown in Table 1. In the univariate analysis, case complexity and age were associated with a divergent SMO. There was no difference between groups for the region of residence or employment category.

A summary of divergence rates is presented in Table 2 according to broad disease categories. Overall, the type of disease was significantly related to the rate of divergence $(p<.001)$. Diseases with four or more diverging opinions are described in Table 3.

The overall divergence rate for orthopedic diseases was $24.7 \%$. Prostate adenoma had a divergence rate of $50 \%$ ( $n=14 / 28$ patients). Regarding gynecological diseases, endometriosis and uterine fibroma had high divergence rates of 60.4 and $47.8 \%$ respectively. In the cancer group, prostate and bladder cancers often showed a divergent second opinion with divergence rates of $34.8 \%$ $(n=16 / 46)$ and $33.3 \%(n=4 / 12)$ respectively.

Among cardiovascular diseases, the divergence rate for coronary artery disease was $66.7 \%$. In the category of endocrine and metabolic diseases, there were five divergent cases for goiter/thyroid nodules and hyperthyroidism (41.7 and $33.3 \%$ divergence rate respectively), while chronic obstructive pulmonary disease had the most (absolute) divergent cases among the respiratory diseases (4/7 divergent cases, $57.1 \%$ ). The full set of results with the list of all diseases is presented in Additional file 1.

The factors associated with a divergent SMO by multivariate analysis are shown in Table 4. Cardiovascular, endocrine/metabolic, gynecological and respiratory diseases were associated with a significantly higher risk of having a divergent opinion (Table 4). Complex cases were also associated with a significantly higher risk of a divergent opinion (Odds ratio (OR) 2.78;95 \% CI, 2.15 to 3.59). Furthermore, the time required to produce an SMO report was significantly longer in complex cases. Model performance was acceptable: C- Statistic AUC 0.706 (0.694 to 0.719) and Nagelkerke pseudo-R2 0.16 $(0.15$ to 0.18$)$. These findings are presented in Additional file 2 .

\section{Discussion}

In this nationwide study with data on 1,552 SMO requests, we found that gynecological, respiratory, 
Table 1 Patient characteristics according to divergence of the second look opinion

\begin{tabular}{|c|c|c|c|c|c|}
\hline \multirow[t]{2}{*}{ Characteristics } & \multirow{2}{*}{$\begin{array}{l}\text { Convergent } \\
N=1050\end{array}$} & \multirow{2}{*}{$\begin{array}{l}\text { Divergent } \\
N=502\end{array}$} & \multirow{2}{*}{$\begin{array}{l}\text { Missing } \mathrm{n} \text { or } \% \\
N=384\end{array}$} & \multirow[t]{2}{*}{$P$-value } & \multirow{2}{*}{$\begin{array}{l}\text { French population (\% } \\
\text { of category in general } \\
\text { population) } \\
N=67,287,241\end{array}$} \\
\hline & & & & & \\
\hline Male Sex & $420(40.1 \%)$ & $178(35.5 \%)$ & $0.2 \%$ & 0.08 & $32,397,179(48.8 \%)$ \\
\hline Specific or exceptional complexity & $208(21.1 \%)$ & $193(39.7 \%)$ & $23.7 \%$ & $<0.0001$ & \\
\hline \multicolumn{6}{|l|}{ Satisfaction with the service provided } \\
\hline Quite satisfied & $27(3.8 \%)$ & $15(3.9 \%)$ & $29.9 \%$ & 0.67 & \\
\hline Not at all satisfied & $4(0.6 \%)$ & $2(0.5 \%)$ & & & \\
\hline Satisfied & $151(21.1 \%)$ & $69(18.2 \%)$ & & & \\
\hline Very satisfied & $532(74.5 \%)$ & $294(77.4 \%)$ & & & \\
\hline Expert recommendation by patient & $675(97.0 \%)$ & $365(97.1 \%)$ & $31.7 \%$ & 0.99 & \\
\hline Choice made by the patient & $722(68.8 \%)$ & $359(71.5 \%)$ & - & 0.27 & \\
\hline Median time required for opinion, days [IQR] & $2.00[0.47,5.16]$ & $2.28[0.66,5.20]$ & $0.3 \%$ & 0.09 & \\
\hline \multicolumn{6}{|l|}{ Region of residence } \\
\hline Ile de France & $295(30.1 \%)$ & $143(30.4 \%)$ & $8.5 \%$ & 0.133 & $12,291,557(18.3 \%)$ \\
\hline Auvergne Rhone Alpes Bourgogne Franche Comte & $119(12.1 \%)$ & $54(11.5 \%)$ & & & $10,858,663(16.1 \%)$ \\
\hline Bretagne Normandie Pays de la Loire Centre Val de Loire & $123(12.7 \%)$ & $82(17.4 \%)$ & & & $13,056,103(19.4 \%)$ \\
\hline Hauts de France Grand Est & $208(21.2 \%)$ & $83(17.7 \%)$ & & & $11,523,797(17.1 \%)$ \\
\hline Nouvelle Aquitaine & $77(7.8 \%)$ & $30(6.4 \%)$ & & & $6,018,424(8.9 \%)$ \\
\hline PACA, Occitanie & $145(14.8 \%)$ & $74(15.7 \%)$ & & & $11,029,432(16.4 \%)$ \\
\hline Corsica $^{a}$ & $5(0.5 \%)$ & $0(0.0 \%)$ & & & $345,867(0.5 \%)$ \\
\hline Overseas territories $^{a}$ & $9(0.9 \%)$ & $4(0.9 \%)$ & & & $2,163,398(3.2 \%)$ \\
\hline \multicolumn{6}{|l|}{ Age groups } \\
\hline Teenagers $<18$ years & $50(4.8 \%)$ & $21(4.2 \%)$ & - & $<0.0001$ & $15,252,608(22.7 \%)$ \\
\hline Adults aged 36 to 50 years & $308(29.3 \%)$ & $136(27.1 \%)$ & & & $12,887,561(19.2 \%)$ \\
\hline Adults aged 19 to 35 years & $239(22.8 \%)$ & $181(36.1 \%)$ & & & $13,177,128(19.6 \%)$ \\
\hline Adults aged 51 to 65 years & $256(24.4 \%)$ & $97(19.3 \%)$ & & & $12,790,894(19.1 \%)$ \\
\hline Older adults aged 66 to 80 years & $183(17.4 \%)$ & $62(12.4 \%)$ & & & $9,206,549(13.7 \%)$ \\
\hline Older adults aged 81 to 95 years & $14(1.3 \%)$ & $5(1.0 \%)$ & & & $3,515,308(5.2 \%)$ \\
\hline \multicolumn{6}{|l|}{ Professional status } \\
\hline Intermediate profession & $248(33.0 \%)$ & $148(38.4 \%)$ & $30.6 \%$ & 0.07 & $14,041,617(20.9 \%)$ \\
\hline Self-employed, business owner or manager & $230(30.6 \%)$ & 95 (24.7\%) & & & $7,373,204(11.0 \%)$ \\
\hline Other & $67(8.9 \%)$ & $39(10.1 \%)$ & & & $487,932(0.7 \%)$ \\
\hline Currently unemployed (job seekers or students) & $57(7.6 \%)$ & $39(10.1 \%)$ & & & $23,912,440(35.5 \%)$ \\
\hline Manal worker & $25(3.3 \%)$ & $11(2.9 \%)$ & & & $5,204,615(7.7 \%)$ \\
\hline Retired & $124(16.5 \%)$ & $53(13.8 \%)$ & & & $16,267,433(24.2 \%)$ \\
\hline
\end{tabular}

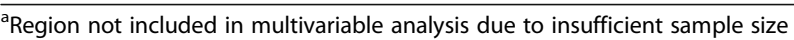

endocrine/metabolic and cardiovascular diseases were more likely to have a divergent SMO. The complexity of the case was also found to be associated with a higher likelihood of a divergent SMO.

In the literature, the main reasons proposed for seeking a SMO were persisting symptoms, absence of diagnosis or the need for confirmation of a diagnosis, the need for more information, questioning the need for surgery [1] (such as total mastectomy), and a desire to change the proposed treatment [6, 7]. In some cases, these reasons are largely independent of the quality of patient-physician relationship, although this could be less frequent in patients with a low education level [21]. Some studies have shown a link between the level of education and the tendency to seek an SMO [9]. Although our study did not record the level of education of patients directly, we found no relation between the patient's employment and the divergent rate in the 
Table $\mathbf{2}$ Divergence rate by family of diseases

\begin{tabular}{|c|c|c|c|c|}
\hline Group & $\begin{array}{l}\text { Convergent (n) } \\
N=1050\end{array}$ & $\begin{array}{l}\text { Divergent (n) } \\
N=502\end{array}$ & $\begin{array}{l}\text { Proportion divergent (\%) } \\
\text { - }\end{array}$ & $\begin{array}{l}\text { Missing (n) } \\
N=384\end{array}$ \\
\hline Orthopedics and rhumatological diseases & 408 & 134 & 24,7 & 131 \\
\hline Cardiovascular diseases & 45 & 29 & 39,2 & 18 \\
\hline Reproductive diseases & 62 & 25 & 28,7 & 21 \\
\hline Nervous system and sensory organ diseases & 106 & 41 & 27,9 & 27 \\
\hline Skin disorders & 17 & 6 & 26,1 & 6 \\
\hline Digestive system diseases & 33 & 16 & 32,7 & 13 \\
\hline Tumours, cancer, hematological diseases & 187 & 48 & 20,4 & 94 \\
\hline Endocrine and metabolic diseases & 38 & 20 & 34,5 & 13 \\
\hline Gynecological diseases & 121 & 150 & 55,4 & 30 \\
\hline Respiratory diseases & 10 & 9 & 47,4 & 4 \\
\hline Urological diseases & 21 & 22 & 51,2 & 27 \\
\hline Other & 2 & 2 & 50,0 & 0 \\
\hline
\end{tabular}

SMO, considering the professional status as a proxy for education level. There was no evidence in our study that those with higher-level jobs requested a SMO more frequently. Other factors previously reported to be associated with the propensity to request a SMO (such as age, sex, socio-economic category, immigrant status and income) were also not found in our study [16].

The divergence rates observed in our study were similar to the literature on SMOs [6]. The divergent rate for orthopedics in our study $(24.7 \%)$ was similar to the rate reported by Chalian et al., which had divergences of categories 4 and 5 ("likely to change patient management") in $26.2 \%$ of musculoskeletal radiological examinations [22]. However, numerous orthopedic complaints (such as low back pain with $45.5 \%$ divergence in our study) were influenced by psychological factors and could fall into the "functional complaint" category, a known source of why SMOs are requested [23].

Regarding endocrine diseases, our findings were also similar to other literature findings, with a $34.5 \%$ divergence rate compared to $28.6 \%$ reported in the specific context of thyroid cytology [24]. The thyroid is known as a high-risk area for misdiagnosis [25], which is consistent with endocrine diseases being associated with therapeutic divergence. Other head and neck region cancers also showed a high percentage of divergent diagnoses [26] (such as salivary glands cancer $2 / 3$ divergent diagnoses in our study, $66.7 \%$ ), although the study sample was small in this subgroup.

For neurological diseases, there was a divergent opinion in $27.9 \%$ of cases in our study, which compared favorably with data from the literature reporting divergent SMO in $59.8 \%$ of patients initially recommended for spine surgery [27]. The divergence rate for urological malignancies (approximately one third of divergence for prostate and bladder) was higher in our study than in the literature [28].

In a study of 286 referrals, Van Such et al. found that the final diagnosis (after review) was better defined in $66 \%$ of cases and differed in $21 \%$ of cases [3]. Other authors reported divergences in $44 \%$ of breast cancer cases and various other ranges likely due to insufficient sample sizes $[4,8,10]$. Some authors reported lower rates of agreement, but mainly in diseases with a predominantly symptomatic presentation such as unspecific pain that may be hard to diagnose and/or treat [5].

Two limitations should be mentioned about the similarity of our results to literature. In our study, the first and second opinions could not be considered as independent. A prior study showed that knowledge of a previous decision can influence second opinion therapeutic strategy [29]. Moreover, in some of the available studies, the second opinion was obtained several days or weeks after the first consultation and the patient's status could have changed between the first and second opinions.

The need for more information has been associated with physician distrust [30], and some patients expected more personalized communication during an SMO consultation [31]. As patients are expected to feel better informed after an SMO, it has been argued that the possibility of this re-examination is part of the new patient-centric medical paradigm [32, 33]. It should be noted that patients increasingly rely on written material available online to get a SMO regarding their diagnosis rather than on health professionals [34, 35].

Lastly, the use of social media (including pages dedicated to healthcare professionals) to obtain a SMO is increasingly frequent and raises ethical concerns with respect to the physicians' responsability [36]. Despite evident limitations, platforms like WhatsApp allow 
Table 3 Class of diseases where at least four cases had divergent second opinions

\begin{tabular}{|c|c|c|c|}
\hline Class of Diseases & Convergent (n) & Divergent (n) & Divergence rate $(\%)$ \\
\hline \multicolumn{4}{|l|}{ Orthopedics and rhumatological diseases } \\
\hline Herniated lumbar disc & 51 & 13 & $20.3 \%$ \\
\hline Degenerative disc disease & 31 & 10 & $24.4 \%$ \\
\hline Lumbago (chronic lumbar pain) & 12 & 10 & $45.5 \%$ \\
\hline Lumbar arthritis & 7 & 6 & $46.2 \%$ \\
\hline Ankle impingement (bone or tissue) & 5 & 5 & $50.0 \%$ \\
\hline Cervical arthritis & 3 & 4 & $57.1 \%$ \\
\hline Fracture of the humerus (consequences included) & 7 & 4 & $36.4 \%$ \\
\hline Fracture of the wrist or forearm (consequences included) & 6 & 4 & $40.0 \%$ \\
\hline Meniscal lesions & 15 & 4 & $21.1 \%$ \\
\hline \multicolumn{4}{|l|}{ Cardiovascular diseases } \\
\hline Coronary artery disease & 4 & 8 & $66.7 \%$ \\
\hline \multicolumn{4}{|l|}{ Reproductive diseases } \\
\hline Female infertility & 51 & 16 & $23.9 \%$ \\
\hline Azoospermia & 4 & 4 & $50.0 \%$ \\
\hline \multicolumn{4}{|l|}{ Nervous system and sensory organ diseases } \\
\hline Adult epilepsy & 4 & 6 & $60.0 \%$ \\
\hline Herniated cervical disc & 18 & 5 & $21.7 \%$ \\
\hline Multiple sclerosis & 6 & 5 & $45.5 \%$ \\
\hline \multicolumn{4}{|l|}{ Digestive system diseases } \\
\hline Crohn's disease & 3 & 5 & $62.5 \%$ \\
\hline \multicolumn{4}{|l|}{ Tumour, cancer, hematological diseases } \\
\hline Prostate cancer & 30 & 16 & $34.8 \%$ \\
\hline Bladder cancer & 8 & 4 & $33.3 \%$ \\
\hline \multicolumn{4}{|l|}{ Endocrine and metabolic diseases } \\
\hline Goitre or thyroid nodules & 7 & 5 & $41.7 \%$ \\
\hline Hyperthyroidism & 10 & 5 & $33.3 \%$ \\
\hline \multicolumn{4}{|l|}{ Gynecological diseases } \\
\hline Endometriosis & 90 & 137 & $60.4 \%$ \\
\hline Uterine fibroma & 12 & 11 & $47.8 \%$ \\
\hline \multicolumn{4}{|l|}{ Respiratory diseases } \\
\hline Chronic obstructive pulmonary disease & 3 & 4 & $57.1 \%$ \\
\hline \multicolumn{4}{|l|}{ Urological diseases } \\
\hline Prostate adenoma & 14 & 14 & $50.0 \%$ \\
\hline Total & 401 & 305 & $43.3 \%$ \\
\hline
\end{tabular}

patients or physicians to rapidly obtain help, for example by requesting expert readings on pictures of ambiguous biopsy material $[37,38]$. In the context of a SMO, teleconsultations may also be used to combine the convenience and speed of not having to commute to a physician with the security of a personalized expertise [39].

A key strength of this study was that it described a large national cohort of patient-initiated SMOs in France. In contrast with most articles, we described a wide range of diseases encompassing several medical domains. On the other hand, our study also had limitations that deserve to be taken into consideration. Firstly, although there was a countrywide representation of cases, selection bias remained. Secondly, the relatively low number of cases and limited descriptive variables precluded a better analysis of the motivating factors for requesting SMO, or the potential for indication bias. Despite the adjustment applied in the multivariate model, our findings preclude all conclusions regarding the motivations for seeking a SMO. 
Table 4 Factors associated with a divergent second medical opinion by multivariate logistic regression analysis

\begin{tabular}{|c|c|c|c|c|}
\hline \multirow{2}{*}{$\frac{\text { Characteristics }}{\text { Class of diseases }}$} & \multirow[t]{2}{*}{ OR } & \multicolumn{2}{|l|}{$95 \% \mathrm{Cl}$} & \multirow[t]{2}{*}{$P$-value } \\
\hline & & & & \\
\hline Oncology and hematological diseases & 1 (Ref) & - & - & \\
\hline Cardiovascular diseases & 2.609 & 1.441 & 4.723 & $<0.0001$ \\
\hline Reproductive diseases & 1.746 & 0.923 & 3.303 & \\
\hline Skin disorders & 1.356 & 0.483 & 3.808 & \\
\hline Digestive system diseases & 1.759 & 0.867 & 3.570 & \\
\hline Endocrine and metabolic diseases & 2.072 & 1.089 & 3.944 & \\
\hline Gynecological diseases & 5.176 & 3.154 & 8.494 & \\
\hline Respiratory diseases & 3.639 & 1.357 & 9.758 & \\
\hline Orthopedics and rhumatological diseases & 1.266 & 0.860 & 1.864 & \\
\hline Nervous system and sensory organ diseases & 1.267 & 0.761 & 2.11 & \\
\hline Urological diseases & 4.246 & 2.053 & 8.782 & \\
\hline \multicolumn{5}{|l|}{ Complexity } \\
\hline Normal or common & 1 (Ref) & - & - & $<0.0001$ \\
\hline Specific/exceptional & 2.784 & 2.157 & 3.592 & \\
\hline Time required for file review & 0.985 & 0.959 & 1.011 & 0.26 \\
\hline \multicolumn{5}{|l|}{ Region of residence } \\
\hline He-de-France & 1 (Ref) & - & - & 0.18 \\
\hline Auvergne-Rhône-Alpes, Bourgogne-Franche-Comte & 1.044 & 0.680 & 1.601 & \\
\hline Bretagne, Normandie, Pays de la Loire, Centre-Val de Loire & 1.64 & 1.121 & 2.399 & \\
\hline Hauts-de-France, Grand Est & 1.125 & 0.784 & 1.613 & \\
\hline Nouvelle-Aquitaine & 0.98 & 0.583 & 1.647 & \\
\hline PACA, Occitanie & 1.209 & 0.817 & 1.79 & \\
\hline \multicolumn{5}{|l|}{ Professional status } \\
\hline Intermediate profession & 1 (Ref) & - & - & 0.39 \\
\hline Self-employed, business owner or manager & 0.78 & 0.563 & 1.082 & \\
\hline Other & 0.915 & 0.557 & 1.502 & \\
\hline Currently unemployed (job seekers or students) & 0.813 & 0.499 & 1.323 & \\
\hline Manual labourer & 0.944 & 0.449 & 1.983 & \\
\hline Retired & 1.291 & 0.743 & 2.244 & \\
\hline \multicolumn{5}{|l|}{ Age category } \\
\hline Adult (36 to 50 years) & 1 (Ref) & - & - & 0.40 \\
\hline Adult (19 to 35 years) & 1.219 & 0.892 & 1.666 & \\
\hline Adult (51 to 65 years) & 0.949 & 0.658 & 1.368 & \\
\hline Child (<18 years) & 1.211 & 0.654 & 2.24 & \\
\hline Older adult (66 to 80 years) & 0.705 & 0.410 & 1.211 & \\
\hline Older adult (81 to 95 years) & 0.573 & 0.185 & 1.771 & \\
\hline Sex Male $($ Ref $=$ Female $)$ & 1.25 & 0.955 & 1.637 & 0.10 \\
\hline
\end{tabular}

We did not distinguish between diagnostic and therapeutic divergence and could also not ascertain if the recommendation of the SMO were followed. Studies consistently report that only approximately $60 \%$ of patients apply recommendations given in the SMO $[14,40]$.
The impact of second opinion programs on public health outcomes appears to be minor for some indications, such as for the prevention of caesarean section where 22 cases per 1,000 deliveries were prevented following a SMO program, without a significant impact on patient satisfaction [41]. Other studies have shown that 
overall satisfaction with SMO programs can be high, irrespective of the presence of a new diagnosis or treatment (95\% satisfaction in one program where treatment was changed in $37 \%$ of cases) [7, 14, 42]. It is worth noting that the participants in our study spontaneously volunteered for a second opinion, and therefore, our results could not be extrapolated at a national level.

\section{Conclusions}

This French nationwide study found a high range of divergent SMO for gynecological, urological, respiratory and endocrine diseases. There is a compelling need for tools to improve care pathways for patients for whom which primary care does not enable satisfactory treatment and produces the need for confirmation of a diagnosis or for more information. Our findings contribute to the ongoing debate on the use of SMOs already initiated for cancer in the French national cancer control plan, with implications for care pathway management and healthcare efficiency strategies. Future research could further explore patient follow-ups after SMOs. Showing a reduction of mortality or hospitalizations would increase the institutional recognition of SMOs and pave the way for a more favorable regulation.

\section{Supplementary Information}

The online version contains supplementary material available at https://doi. org/10.1186/s12913-021-06936-w.

Additional file 1. Proportion of divergent diagnoses in the second medical opinion, by disease.

Additional file 2. Comparison of patient characteristics according to case complexity.

\section{Acknowledgements}

The authors would like to thank Sarina Yaghobian and AcaciaTools for their medical writing and reviewing services.

\section{Authors' contributions}

Conceptualization: SS, IA, LD; Formal Analysis: LD, SS; Funding Acquisition: IA; Investigation: SS, IA; Methodology: JC, SS; Project Administration: SS, IA, JC, PD, PD, LD. All authors have read and approved the manuscript.

\section{Funding}

None.

\section{Availability of data and materials}

All data material can be accessed upon request to the first author Dr Stéphane Sanchez at the following email address stephane.sanchez@hcssante.fr.

\section{Declarations}

\section{Ethics approval and consent to participate}

The SMO platform received approval from the French national commission for data privacy (Commission Nationale Informatique et Libertés, CNIL) and patients provided informed consent that their anonymous data may be used for research and quality improvement purposes. No additional approvals were required according to the French legislation as it was an observational study based on medical records. All methods were performed in accordance with the relevant guidelines and regulations (Declarations of Helsinki).
Consent for publication

Not applicable.

\section{Competing interests}

Isabelle Adamowicz, Philippe Denormandie, Pierre Denys, and Laurent Degos are non-remunerated scientific board member of the SMO platform evaluated in this study.

\section{Author details}

${ }^{1}$ Public Health and Performance Department, Champagne Sud Hospitals, 101 avenue Anatole France, 10000 Troyes, France. ${ }^{2}$ Scientific Department, Deuxième Avis, Paris, France. ${ }^{3}$ Orthopedic Department, Raimond Poincaré Hospital, APHP, Garches, France. ${ }^{4}$ Urology and Neurology Rehabilitation Department, Raimond Poincaré Hospital, APHP, Garches, France. ${ }^{5}$ French academy of sciences, Paris, France.

Received: 26 May 2021 Accepted: 24 August 2021

Published online: 01 September 2021

\section{References}

1. Benson WE, Regillo CD, Vander JF, Tasman W, Smith AF, Brown GC, et al. Patient-initiated second medical opinions: their necessity and economic cost. Retina. 2001;21(6):633-8.

2. Hahm GK, Niemann TH, Lucas JG, Frankel WL. The value of second opinion in gastrointestinal and liver pathology. Arch Pathol Lab Med. 2001;125(6): 736-9.

3. Van Such M, Lohr R, Beckman T, Naessens JM. Extent of diagnostic agreement among medical referrals. J Eval Clin Pract. 2017;23(4):870-4.

4. Garcia D, Spruill LS, Irshad A, Wood J, Kepecs D, Klauber-DeMore N. The Value of a Second Opinion for Breast Cancer Patients Referred to a National Cancer Institute (NCI)-Designated Cancer Center with a Multidisciplinary Breast Tumor Board. Ann Surg Oncol. 2018;25(10):2953-7.

5. Burger PM, Westerink J, Vrijsen BEL. Outcomes of second opinions in general internal medicine. PloS One. 2020;15(7):e0236048.

6. Payne VL, Singh H, Meyer AND, Levy L, Harrison D, Graber ML. Patientinitiated second opinions: systematic review of characteristics and impact on diagnosis, treatment, and satisfaction. Mayo Clin Proc. 2014;89(5):687-96.

7. Meyer AND, Singh $\mathrm{H}$, Graber ML. Evaluation of outcomes from a national patientinitiated second-opinion program. Am J Med. 2015;128(10):1138.e25-33.

8. Tosteson ANA, Yang Q, Nelson HD, Longton G, Soneji SS, Pepe M, et al. Second opinion strategies in breast pathology: a decision analysis addressing over-treatment, under-treatment, and care costs. Breast Cancer Res Treat. 2018;167(1):195-203.

9. Hillen MA, Medendorp NM, Daams JG, Smets EMA. Patient-driven second opinions in oncology: a systematic review. Oncologist. 2017;22(10):1197-211.

10. Coffey K, Mango V, Keating DM, Morris EA, D'Alessio D. The impact of patient-initiated subspecialty review on patient care. J Am Coll Radiol JACR. 2018;15(8):1109-15.

11. Wieske L, Wijers D, Richard E, Vergouwen MDI, Stam J. Second opinions and tertiary referrals in neurology: a prospective observational study. J Neurol. 2008;255(11):1743-9.

12. Heuss SC, Schwartz BJ, Schneeberger AR. Second opinions in psychiatry: a review. J Psychiatr Pract. 2018;24(6):434-42.

13. Gertman PM, Stackpole DA, Levenson DK, Manuel BM, Brennan RJ, Janko GM. Second opinions for elective surgery: the mandatory Medicaid program in Massachusetts. N Engl J Med. 1980;302:1169-74.

14. Weyerstraß J, Prediger B, Neugebauer E, Pieper D. Results of a patientoriented second opinion program in Germany shows a high discrepancy between initial therapy recommendation and second opinion. BMC Health Serv Res. 2020;20(1):237.

15. Shmueli L, Davidovitch N, Pliskin JS, Balicer RD, Hekselman I, Greenfield G. Seeking a second medical opinion: composition, reasons and perceived outcomes in Israel. Isr J Health Policy Res. 2017;6:67.

16. Shmueli L, Shmueli E, Pliskin JS, Balicer RD, Davidovitch N, Hekselman I, et al. Second opinion utilization by healthcare insurance type in a mixed private-public healthcare system: a population-based study. BMJ Open. 2019;9(7):e025673.

17. Corrias G, Huicochea Castellanos S, Merkow R, Langan R, Balachandran V, Ragucci $M$, et al. Does second reader opinion affect patient management in pancreatic ductal adenocarcinoma? Acad Radiol. 2018;25:825-32. 
18. Tomaszewski JE, Bear HD, Connally JA, Epstein JI, Feldman M, Foucar K, et al. Consensus conference on second opinions in diagnostic anatomic pathology. Am J Clin Pathol. 2000;114(3):329-35.

19. Strosberg C, Gibbs J, Braswell D, Leslie RR, Messina J, Centeno BA, et al. Second opinion reviews for cancer diagnoses in anatomic pathology: a comprehensive cancer center's experience. Anticancer Res. 2018;38(5):2989-94.

20. Lopez-Beltran A, Canas-Marques R, Cheng L, Montironi R. Histopathologic challenges: the second OPINION issue. Eur J Surg Oncol. 2019;45(1):12-5.

21. Cecon N, Hillen MA, Pfaff H, Dresen A, Groß SE. Why do newly diagnosed breast cancer patients seek a second opinion? - Second opinion seeking and its association with the physician-patient relationship. Patient Educ Couns. 2019;102(5):998-1004.

22. Chalian M, Del Grande F, Thakkar RS, Jalali SF, Chhabra A, Carrino JA Second-opinion subspecialty consultations in musculoskeletal radiology. Am J Roentgenol. 2016;206(6):1217-21.

23. Mustafa MK, Bijl M, Gans ROB. What is the value of patient-sought second opinions? Eur J Intern Med. 2002;13(7):445-7.

24. Gerhard R, Boerner SL. The value of second opinion in thyroid cytology: a review. Cancer Cytopathol. 2014;122(8):611-9.

25. Mullin MH, Brierley DJ, Speight PM. Second opinion reporting in head and neck pathology: the pattern of referrals and impact on final diagnosis. Oral Surg Oral Med Oral Pathol Oral Radiol. 2015;119(6):656-60.

26. Jones K, Jordan RCK. Patterns of second-opinion diagnosis in oral and maxillofacial pathology. Oral Surg Oral Med Oral Pathol Oral Radiol Endodontol. 2010;109(6):865-9.

27. Lenza M, Buchbinder R, Staples MP, dos Santos OFP, Brandt RA, Lottenberg $\mathrm{CL}$, et al. Second opinion for degenerative spinal conditions: an option or a necessity? A prospective observational study. BMC Musculoskelet Disord. 2017;18(1):354

28. Wayment RO, Bourne A, Kay P, Tarter TH. Second opinion pathology in tertiary care of patients with urologic malignancies. Urol Oncol. 2011;29(2): 194-8.

29. Vashitz G, Pliskin JS, Parmet Y, Kosashvili Y, Ifergane G, Wientroub S, et al. Do first opinions affect second opinions? J Gen Intern Med. 2012;27:1265-71.

30. Groß SE, Hillen MA, Pfaff H, Scholten N. Second opinion in medical encounters - a study among breast cancer patients. Patient Educ Couns. 2017;100(1):1990-5.

31. Goldman RE, Sullivan A, Back AL, Alexander SC, Matsuyama RK, Lee SJ. Patients' reflections on communication in the second-opinion hematologyoncology consultation. Patient Educ Couns. 2009;76(1):44-50.

32. Shaikh S, Bafana R, Halabi SS. Concierge and second-opinion radiology: review of current practices. Curr Probl Diagn Radiol. 2016:45(2):111-4.

33. de Takats D. Getting a second opinion: whose side are you on? BMJ. 2020; 370:m3253.

34. $\mathrm{Ng} J$ Y, Vacca A, Jain T. The quality of online consumer health information at the intersection of complementary and alternative medicine and arthritis. Adv Rheumatol. 2021;61(1):1-17.

35. Chen W, Lee K-H, Straubhaar JD, Spence J. Getting a second opinion: Social capital, digital inequalities, and health information repertoires: Journal of the American Society for Information Science and Technology. J Assoc Inf Sci Technol. 2014;65(12):2552-63.

36. Caruso Brown AE, Arthur JD, Mutrie LH, Lantos JD. Seeking a second opinion on social media. Pediatrics. 2019;144(5):e20190817.

37. Sarode SC, Sarode GS, Anand R, Patil S, Unadkat H. WhatsApp is an effective tool for obtaining second opinion in oral pathology practice. J Oral Pathol Med. 2017:46(7):513-9.

38. Khalele BA. Regarding 'WhatsApp is an effective tool for obtaining second opinion in oral pathology practice.' J Oral Pathol Med. 2017:46(7):558-558.

39. Lozzi GP, Soyer HP, Massone C, Micantonio T, Kraenke B, Fargnoli MC, et al. The additive value of second opinion teleconsulting in the management of patients with challenging inflammatory, neoplastic skin diseases: a best practice model in dermatology? J Eur Acad Dermatol Venereol. 2007;21(1):30-4.

40. Okamoto S, Kawahara K, Okawa A, Tanaka Y. Values and risks of second opinion in Japan's universal health-care system. Health Expect. 2015;18(5): 826-38

41. Althabe F, Belizán JM, Villar J, Alexander S, Bergel E, Ramos S, et al. Mandatory second opinion to reduce rates of unnecessary caesarean sections in Latin America: a cluster randomised controlled trial. Lancet. 2004; 363(9425):1934-40.
42. Wijers D, Wieske L, Vergouwen MDI, Richard E, Stam J, Smets EMA. Patient satisfaction in neurological second opinions and tertiary referrals. J Neurol. 2010;257(11):1869-74.

\section{Publisher's Note}

Springer Nature remains neutral with regard to jurisdictional claims in published maps and institutional affiliations.
Ready to submit your research? Choose BMC and benefit from:

- fast, convenient online submission

- thorough peer review by experienced researchers in your field

- rapid publication on acceptance

- support for research data, including large and complex data types

- gold Open Access which fosters wider collaboration and increased citations

- maximum visibility for your research: over $100 \mathrm{M}$ website views per year

At BMC, research is always in progress.

Learn more biomedcentral.com/submissions 